DOI: $10.17805 / z p u .2018 .3 .20$

\title{
Проблема оценки эффективности социального взаимодействия
}

\author{
T. С. ВАВАКИНА \\ ИНСТИТУТ ПСИХОЛОГИИ РАН
}

Отмечается, что взаимодействие де-факто является одной из базовых категорий социальной психологии. Предпринимается попытка определить место социального взаимодействия в ряду категорий: деятельность, общение, отношения. Автором предлагается теоретическая модель социального взаимодействия. В структуре социального взаимодействия выделяется три уровня анализа: микроуровень, мезоуровень и макроуровень. На микроуровне анализируется единица социального взаимодействия - элементарное социальное взаимодействие - пара сопряженных социальных действий субъектов. На мезоуровне социальное взаимодействие представлено ситуацией взаимодействия - совокупностью элементарных социальных взаимодействий. Макроуровень уровень складывается из совокупности всех ситуаций взаимодействия между субъектами. Формируются устойчивые взаимосвязи между субъектами - определенные отношения между ними. Предлагается теоретический подход к оценке эффективности социального взаимодейст- 
вия. Подчеркивается важность учета субъективной оценки эффективности социального взаимодействия: рациональной оценки достигнутых результатов взаимодействия; оценки эмоциональных переживаний, связанных с данным взаимодействием; ценностносмыслового компонента - удовлетворенности процессом и результатом социального взаимодействия; оценки перспектив данного взаимодействия, готовности прилагать усилия для развития отношений между участниками взаимодействия.

Ключевые слова: социальное взаимодействие; партнерство; деятельность; общение; психологическое отношение; мотивация; эффективность взаимодействия

\section{ВВЕАЕНИЕ}

И сходя из известных в науке определений понятия «взаимодействие», можно заключить, что оно более широкое по объему, чем связанные с ним понятия «общение», «отношения» и «совместная деятельность». Направленность взаимодействия характеризуется его объектом (предметом), целями и результатом (последствиями). В качестве цели взаимодействия авторы обычно указывают на целенаправленное изменение свойств предмета совместной деятельности, выступающего объектом воздействия, либо на изменение свойств субъектов взаимодействия и отношений между ними. Именно такое основание лежит в основе разделения явлений общения и совместной деятельности. По поводу соотношения этих понятий и лежащих в их основе явлений существуют разные представления. Одни авторы непосредственно связывают эти два понятия, рассматривая общение как подчиненный элемент совместной деятельности, другие их разводят, определяя как относительно самостоятельные. Мы придерживаемся второй точки зрения, полагая, что социальное взаимодействие реализуется в деятельности и общении субъектов.

В данной публикации мы уделим основное внимание проблеме оценки социального взаимодействия и его эффективности. Аля этого очень кратко рассмотрим схему анализа социального взаимодействия, обозначим некоторые вопросы мотивации, представим наше видение проблемы изучения эффективности социального взаимодействия.

\section{ТЕОРЕТИЧЕСКАЯ МОАЕАЬ СОЦИАИЬНОГО ВЗАИМОАЕЙСТВИЯ}

Предмет нашего исследования - партнерство, которое мы рассматриваем как одну из форм деловой активности субъектов экономической деятельности (Позняков, Вавакина, 2009). Родовым, более общим по отношению к понятию «партнерство» выступает понятие «социальное взаимодействие», т. е. взаимодействие между индивидами и группами как социальными субъектами. Социальное взаимодействие де-факто является одной из базовьх категорий сочиальной психологии. По мнению А. А. Журавлева, «в социальной психологии, однако, категория взаимодействия исследована недостаточно, не выделены социально-психологические характеристики, которые бы позволяли его конкретно оценивать и описывать практическое взаимодействие людей» (Журавлев, 2005: 102). Поэтому, прежде чем представить подход, который мы ис-пользовали в оценке эффективности партнерства, нам необходимо кратко обозначить теоретическую модель сочиального взаимодействия.

Аовольно непростой вопрос: как же определить социальное взаимодействие в психологии? Ведь и предельно краткий акт коммуникации может интерпретироваться как взаимодействие, и взаимоотношения между людьми на протяжении всей их жизни. В свое время Б. Ф. Аомов предложил очень понятную уровневую схему для анализа общения (Аомов, 1984). Аналогичным образом мы будем рассматривать и структуру 
социального взаимодействия. Выделим три уровня анализа социального взаимодействия: микроуровень, мезоуровень и макроуровень. Рассмотрение этой схемы мы начнем от простого к сложному.

Начинается любое социальное взаимодействие на микроуровне. Самое простое социальное взаимодействие - элементарное соииальное взаимодействие - можно представить как пару сопряженных социальных действий субъектов. Именно социальное действие, которое М. Вебер считал самым әлементарным, что только есть в общественной жизни, лежит в основе социального взаимодействия. Социальное действие - это любое человеческое действие: деяние, недеяние, претерпевание, внешнее или внутреннее. Важно, что действующий человек непременно связывает с ним субъективный смысл (Вебер, 1990). Однако отдельно взятое социальное действие не может являться взаимодействием, даже самым элементарным. Поэтому единицей социального взаимодействия является элементарное социальное взаимодействие. Здесь стоит отметить, что речь идет именно о сопряженных социальных действиях субъектов, т. е. социальное действие второго участника взаимодействия непременно является ответом на социальное действие первого. Если взаимодействие продолжается, то в следующем элементарном взаимодействии роли участников меняются. Теперь уже социальное действие второго участника, которое, по сути, является обратной связью Аля первого, будет открывать очередное элементарное взаимодействие. Так запускается цепочка взаимообусловленных элементарных социальных действий, которые могут складываться в небольшие эпизоды или развернутые ситуации взаимодействия. Таким образом, на микроуровне уместно рассмотрение и отдельного социального действия субъекта, и элементарного социального взаимодействия, и небольших эпизодов, которые не переросли в ситуацию взаимодействия.

На мезоуровне социальное взаимодействие представлено ситуачией взаимодействия, т. е. логически завершенной совокупностью элементарных социальных взаимодействий. Ситуация взаимодействия зачастую имеет довольно четко выраженные начало и конец, которые могут быть обозначены принятыми в сообществе социокультурными маркерами: постановка задачи, подведение итогов, приветствие, прощание и т. п. В отличие от әпизода, ситуация взаимодействия, как правило, преследует определенные цели, а в процессе участники решают как поставленные заранее, так и возникающие по ходу задачи. Ситуации могут быть оценены с точки зрения результата. Независимо от того, достигнута ли поставленная цель, ситуация взаимодействия тем не менее ограничена по времени.

На макроуровне процесс взаимодействия представлен на более или менее продолжительных этапах жизни человека. Речь идет прежде всего о формирования устойчивых взаимосвязей между субъектами, включенными в ситуации социального взаимодействия, - определенных отношений (связей) между ними, которые формируются по совокупности всех частных ситуаций социального взаимодействия субъектов.

В наших дальнейших рассуждениях мы исходим из того, что социальное взаимодействие - это базовая категория социальной психологии. Социальное взаимодействие реализуется в деятельности (индивидуальной или совместной) и общении субъектов. Возможны различные конфигурации социального взаимодействия в соответствии с целями и задачами, которые решает данное взаимодействие. Так, социальное взаимодействие может быть представлено: совместной деятельностью в совокупности с минимально выраженным общением участников; преимущественно эмоциональным неформальным общением без выраженного деятельностного компонента; инди- 
видуальной деятельностью одного или нескольких участников, сопровождающейся общением, обменом мнениями, суждениями, оценками; множеством других вариантов взаимодействия.

Поскольку мы изучаем такое социальное взаимодействие, как партнерство, нам неизбежно придется проводить параллели с основательно изученным феноменом совместной деятельности. А. $\Lambda$. Журавлев разводит понятия совместной деятельности и взаимодействия, отмечая, что «взаимодействие между людьми (или общение как одна из конкретных его форм) может иметь место и при выполнении относительно независимых индивидуальных деятельностей» (Журавлев, 2005: 104). Аалеко не всякое взаимодействие субъектов может быть ассоциировано с совместной деятельностью, а только предметно-направленное. «Целевое взаимодействие людей одновременно предполагает и отношение их как субъектов, и совместное их отношение к общему объекту деятельности» (там же).

\section{НЕСКОАБКО САОВ О МОТИВАЦИИ}

Социальное взаимодействие и оценка его эффективности во многом будут зависеть от мотивации участников. Это не самые очевидные критерии оценки әффективности социального взаимодействия, но без учета мотивации участников, без понимания того, что именно предполагалось достичь в данном конкретном взаимодействии, оценивать результаты сложно. Это связано с тем, что далеко не каждое социальное взаимодействие подчинено исключительно рациональным и четко определенным целям. Рассуждения о рациональности и иррациональности социального взаимодействия приводят нас к пониманию того, что спектр мотивов, побуждающих людей к взаимодействию, гораздо шире и не ограничивается решением исключительно утилитарно-прагматических задач (Позняков, Вавакина, 2011, 2016; Позняков, Груздева, 2013 и ар.).

Аля анализа проблемы в первом приближении можно опереться на типы социального действия по степени их рациональности и осознанности, предложенные М. Beбером: целерациональное социальное действие, ценностно-рациональное действие, аффективное действие и традиционное действие (Вебер, 1990). И если в случае целерационального действия действительно наиболее важно достижение определенной цели, то по отношению к другим типам социального действия это слабо применимо или не применимо вовсе. С определенной натяжкой к рациональному можно отнести ценностно-рациональное действие. Однако в этом случае собственно результат отходит на второй план, для субъекта важно совершение самого действия, которое представляется значимым в соответствии с ценностно-смысловой сферой личности, т. е. непосредственно мотивируется ценностями и смыслами самого субъекта. При анализе социального взаимодействия невозможно игнорировать и те действия, которые совершаются под влиянием эмоций (аффективное действие) и или в соответствии с требованиями социальных норм, или по привычке (традиционное действие). Таким образом, в основе социального взаимодействия могут лежать рациональные цели, эмоциональные побуждения, следование устоявшимся стереотипам и, что наиболее важно, по нашему мнению, ценности и смыслы участников взаимодействия. Справедливости ради стоит отметить, что, если речь идет о более или менее развернутой во времени ситуации взаимодействия или совокупности ситуаций, все эти основания социального взаимодействия в той или иной мере обязательно будут представлены. 
Кроме того, Б. Ф. Аомов обращал внимание на то, что «сочетание индивидуальных мотивов может повлечь за собой изменение первоначальных мотивов, “обогащение" мотивационной сферы каждого из участников взаимодействия» (Аомов, 1981: 19-20).

Таким образом, можно говорить о полимотивированности социального взаимодействия. Безусловно, остается ряд вопросов по мотивации, но это тема для отдельного обсуждения. В данной статье мы сконцентрируем свое внимание на оценке эффективности.

\section{ТЕОРЕТИЧЕСКИЙ ПОАХОА К ОЦЕНКЕ ЭФФЕКТИВНОСТИ СОЦИААЬНОГО ВЗАИМОАЕЙСТВИЯ}

Проблема оценки эффективности социального взаимодействия заключается в множественности получаемых в ходе этого взаимодействия результатов. Эффективность совместной деятельности понимается прежде всего как «результативность (продуктивность)» (Журавлев, 2005: 92) в силу того, что совместная деятельность по сути своей целерациональна. В свою очередь, социальное взаимодействие принципиально не может быть рассмотрено исключительно с позиции получения какого-то одного конкретного результата.

Кроме того, эффективность взаимодействия может исследоваться с двух принципиально разных позиций: внешней (экспертной) оценки и самооценки. Интерпретация эффективности социального взаимодействия с точки зрения внешнего наблюдателя (эксперта) имеет некоторые ограничения, связанные с неочевидностью истинных мотивов субъекта, включенного во взаимодействие. Поскольку внешне наблюдаемое поведение далеко не всегда однозначно объясняет мотивы человека, то и оценка эффективности может быть представлена лишь исходя из неких формальных критериев успешности, которые представляются значимыми эксперту. В ряде случаев это уместно и даже полезно, кроме того, такая оценка может работать как обратная связь от не включенного во взаимодействие наблюдателя. Но надо учитывать, что в этом случае невозможно делать выводы об успешности с позиции самого человека, его удовлетворенности результатом, а главное - самим процессом взаимодействия.

Необходимо также отметить еще некоторые существенные моменты. А именно внешняя (экспертная) оценка применима лишь на уровне ситуации взаимодействия. На уровне отдельного социального действия или әлементарного социально взаимодействия судить об эффективности, как правило, невозможно. Если же мы говорим об эффективности отношений (как связи) между субъектами, формирующихся по совокупности всех ситуаций социального взаимодействия, в которые они были включены, то самооценка представляется единственным адекватным способом получения информации.

А. $\Lambda$. Журавлев отмечает, что «большое значение имеет не только общий объективный результат, но и его субъективное отражение коллективным субъектом» (Журавлев, 2005: 96). Этот результат «может быть выражен через субъективные групповые оценки достигнутого, через социальные представления и отношение к нему. ОАнако этот аспект также недостаточно изучен» (там же).

Самооценка эффективности социального взаимодействия может быть проанализирована с точки зрения когнитивного, аффективного, конативного и ценностносмыслового компонентов психологического отношения. Когнитивный компонент представлен рациональной оценкой достигнутых результатов взаимодействия. Аффективный компонент - оценкой эмоциональных переживаний, связанных с данным 
взаимодействием. Безусловно, важна удовлетворенность - позитивная оценка различных аспектов жизни, имеющих особое значение для индивида, т. е. выделяется ценностно-смысловой компонент, связанный с удовлетворенностью процессом и результатом социального взаимодействия. Конативный компонент - намерением завершить или продолжать данное взаимодействие и готовностью прилагать усилия для развития отношений между участниками взаимодействия.

В этом отношении представлен и временной континуум психологического отношения к прошлому, настоящему и будущему (Позняков, 2013). На уровне анализа ситуации взаимодействия самооценка эффективности являет собой прежде всего ретроспективный взгляд на определенную ситуацию социального взаимодействия. В этом случае, как правило, в первую очередь речь идет о субъективной оценке результатов завершенной ситуации взаимодействия. Оценка эффективности социального взаимодействия на уровне отношений, складывающихся в результате череды ситуаций взаимодействия, в равной мере может включать ретроспективную оценку уже полученных результатов на основе опыта взаимодействия, оценку отношений между субъектами на текущий момент времени и оценку перспектив развития этих отношений.

\section{ЗАКАЮЧЕНИЕ}

Поскольку в основе любого социального взаимодействия лежит социальное действие, с которым субъект непременно связывает свой собственный смысл, то на первый план с точки зрения эффективности взаимодействия безусловно выходит самооценка. В этом случае речь идет об эффективном взаимодействии с точки зрения самого субъекта, об оценке результатов и его личных достижений, полученных в ходе взаимодействия, удовлетворенности не только результатом, но и самим процессом взаимодействия, о положительных или отрицательных эмоциях, связанных с этим взаимодействием, о готовности к продолжению взаимодействия в будущем, поддержанию и развитию отношений с другими участниками взаимодействия.

Мы полагаем правильным и обоснованным учет всех этих нюансов. Наши исследования партнерства показали, что даже деловое партнерство в сфере бизнеса подразумевает широкий диапазон критериев әффективности взаимодействия (Вавакина, Позняков, 2014ab). Впрочем, это относится и к оценке отношений партнерства в других сферах жизнедеятельности (Вавакина, 2018). Включенность во взаимодействие как минимум двух субъектов предполагает рассмотрение проблемы не только с точки зрения объективных критериев оценки результатов взаимодействия, но прежде всего учет субъективных оценок участников данного взаимодействия.

\section{СПИСОК АИТЕРАТУРЫ}

Вавакина, Т. С. (2018) Отношения партнерства в деловой и личной сферах жизни человека: удовлетворенность и успешность // Человеческий фактор: Социальный психолог. № 1 (35). С. 239-246.

Вавакина, Т. С., Позняков, В. П. (2014а) Психологические факторы эффективности делового партнерства // Прикладная юридическая психология. № 2. С. 113-124.

Вавакина, Т. С., Позняков, В. П. (2014b) Отношение предпринимателей к принципам и нормам социального взаимодействия и оценка эффективности делового партнерства // Знание. Понимание. Умение. № 2. С. 158-168.

Вебер, М. (1990) Избранные произведения. М. : Прогресс. 808 с.

Журавлев, А. А. (2005) Психология совместной деятельности. М. : ИзА-во «Институт психологии РАН». 640 c. 
Иомов, Б. Ф. (1981) К проблеме деятельности в психологии // Психологический журнал. T. 2. № 5. C. 3-22.

Иомов, Б. Ф. (1984) Методологические и теоретические проблемы психологии. М. : Наука. 444 с.

Позняков, В. П. (2013) Развитие теории отношений в современной отечественной социальной психологии // Психологический журнал. Т. 34. № 4. С. 30-35.

Позняков, В. П., Вавакина, Т. С. (2009) Аеловое партнерство как одна из форм деловой активности предпринимателей // Знание. Понимание. Умение. № 4. С. 36-43.

Позняков, В. П., Вавакина, Т. С. (2011) Типы психологического отношения российских предпринимателей к деловому партнерству // Знание. Понимание. Умение. № 2. С. 100-104.

Позняков, В. П., Вавакина, Т. С. (2016) Психология делового партнерства: теория и эмпирические исследования. М. : Изд-во «Институт психологии РАН». 320 с.

Позняков, В. П., Груздева, Е. А. (2013) Социально-психологические факторы ответственного отношения предпринимателей к другим участникам делового взаимодействия // Знание. Понимание. Умение. №3. С. 226-235.

Аата поступления: 03.05.2018 2.

\section{ASSESSMENT ISSUE OF SOCIAL INTERACTION EFFICIENCY \\ T. S. VAVAKINA \\ RAS INSTITUTE OF PSYCHOLOGY}

It is noted that interaction de facto is one of the basic categories of social psychology. The paper attempts to define the place of social interaction among the categories of activity, communication, and relations. The author proposes a theoretical model of social interaction. In the structure of social interaction, three levels of analysis are identified: microlevel, mesolevel, and macrolevel. At the microlevel of social interaction - elementary social interaction, - a pair of interfaced social actions of subjects is analyzed as a unit of social interacton. At the mesolevel, social interaction is represented by an interaction situation - a set of elementary social interactions. Macrolevel comprises the set of all situations of interaction between subjects. Steady interrelations between subjects are formed, i.e. certain relations between them. It is proposed that a theoretical approach should be applied to the assessment of efficiency of social interaction. The author emphasizes the importance of considering subjective judgment of the efficiency of social interaction: rational assessment of the achieved results of interaction; evaluation of the emotional experiences connected with this interaction; the valuesemantic component - satisfaction with the process and result of social interaction; prospective assessment of this interaction, readiness to make efforts to develop relations between the participants of interaction.

Keywords: social interaction; partnership; activity; communication; psychological attitude; motivation; efficiency of interaction

\section{REFERENCES}

Vavakina, T. S. (2018) Otnosheniya partnerstva v delovoy i lichnoy sferah zhizni cheloveka: udovletvorennost i uspeshnost. Chelovecheskiy faktor: Sotsialnyiy psibolog, no. 1 (35), pp. 239-246. (In Russ.).

Vavakina, T. S. and Poznyakov, V. P. (2014a) Psihologicheskie faktoryi effektivnosti delovogo partnerstva. Prikladnaya yuridicheskaya psibologiya, no. 2, pp. 113-124. (In Russ.).

Vavakina, T. S. and Poznyakov, V. P. (2014b) Otnoshenie predprinimateley k printsipam i normam sotsialnogo vzaimodeystviya i otsenka effektivnosti delovogo partnerstva. Znanie. Ponimanie. Umenie, no. 2, pp. 158-168. (In Russ.).

Veber, M. (1990) Izbrannyie proizvedeniya. Moscow, Progress Publ. 808 p. (In Russ.).

Zhuravlev, A. L. (2005) Psibologiya sovmestnoy deyatelnosti. Moscow, Institute of Psychology of RAS Publ. 640 p. (In Russ.). 
Lomov, B. F. (1981) K probleme deyatelnosti v psihologii. Psibologicheskiy zhurnal, vol. 2, no. 5, pp. 3-22. (In Russ.).

Lomov, B. F. (1984) Metodologicheskie i teoreticheskie problemyi psibologii. Moscow, Nauka Publ. 444 p. (In Russ.).

Poznyakov, V. P. (2013) Razvitie teorii otnosheniy v sovremennoy otechestvennoy sotsialnoy psihologii. Psibologicheskiy zhurnal, vol. 34, no. 4, pp. 30-35. (In Russ.)

Poznyakov, V. P. and Vavakina, T. S. (2009) Delovoe partnerstvo kak odna iz form delovoi aktivnosti predprinimatelei [Business partnership as one of the forms of business activity of the enterprises]. Znanie. Ponimanie. Umenie, no. 4, pp. 36-43. (In Russ.).

Poznyakov, V. P. and Vavakina, T. S. (2011) Tipyi psihologicheskogo otnosheniya rossiyskih predprinimateley k delovomu partnerstvu. Znanie. Ponimanie. Umenie, no. 2, pp. 100-104. (In Russ.).

Poznyakov, V. P. and Vavakina, T. S. (2016) Psibologiya delovogo partnerstva: teoriya $i$ empiricheskie issledovaniya. Moscow, Institute of Psychology of RAS Publ. 320 p. (In Russ.)

Poznyakov, V. P. and Gruzdeva, E. A. (2013) Social'no-psichologicheskie factory otvetstvennogo otnosheniia predprinimatelei k drugim uchastnikam delovogo vzaimodeistviia. Znanie. Ponimanie. Umenie, no. 3, pp. 226-234. (In Russ.).

Submission date: 03.05.2018.

Вавакина Татьяна Сергеевна - кандидат психологических наук, ассоциированный сотрудник лаборатории социальной и экономической психологии Института психологии РАН. Адрес: 129366, Москва, ул. Ярославская, А. 13. Тел.: +7 (495) 683-59-30. Эл. aдpec: tvavakina@mail.ru

Vavakina Tatyana Sergeyevna, Candidate of Psychology, Associated Employee, Laboratory of Social and Economic Psychology, RAS Institute of Psychology. Postal address: 13, Yaroslavskaya St., Moscow, Russian Federation, 129366. Tel.: +7 (495)683-59-30. E-mail: tvavakina@mail.ru 